\title{
Dynamic Behavior of Alternative Separation Processes for Ethanol Dehydration by Extractive Distillation
}

\author{
César Ramírez-Márquez, ${ }^{\dagger}$ Juan Gabriel Segovia-Hernández, ${ }^{*}{ }^{\dagger}$ Salvador Hernández, ${ }^{\dagger}$ \\ Massimiliano Errico, ${ }^{\ddagger}$ and Ben-Guang Rong ${ }^{\S}$ \\ ${ }^{\dagger}$ Universidad de Guanajuato, Campus Guanajuato, Division de Ciencias Naturales y Exactas, Departamento de Ingenieria Quimica, \\ Noria Alta S/N, Guanajuato 20256, Mexico \\ ${ }^{\ddagger}$ Università degli Studi di Cagliari, Dipartimento di Ingegneria Meccanica, Chimica e dei Materiali, Via Marengo 2, \\ 09123 Cagliari, Italy \\ ${ }^{\S}$ University of Southern Denmark, Department of Chemical Engineering, Biotechnology and Environmental Technology, \\ Niels Bohrs Allé 1, DK-5230 Odense M, Denmark
}

ABSTRACT: Ethanol is attracting the attention of researchers because of its potential in reducing the dependence on crude oil together with the possible reduction in the pollution associated with the combustion process. The ethanol dehydration process is significant in terms of its production cost. Recently, new distillation sequences have been proposed for the separation of pure ethanol from the fermentation broth. Extending the concept of thermally coupled structures and column sections recombination, already successfully applied to ideal mixtures, it was possible to generate new distillation sequences for azeotropic mixtures. Those configurations are proven to exhibit lower energy consumption together with reduced capital cost compared to the classical sequence proposed in the literature. The aim of this work is the study of the controllability properties under closed-loop operation. Simulation results indicate that the presence of a side stream in extractive distillation sequences does not necessarily provide operational disadvantages; additionally, results also suggest that control properties are ruled by the kind of solvent used.

\section{INTRODUCTION}

Renewable energy supply, climate change, and environmental pollution have been the main agenda in international dialogues and forums nowadays. Because of the political instability in most of the oil-exporting countries, the price of crude oil is escalating to more than 96 US\$ per barrel. The request for affordable and environmental friendly energy sources is more than ever a necessity. Besides, the usage of fossil fuels such as diesel and gasoline increases the greenhouse gas emissions contributing to environmental issues, like global warming, acid rain, and human health deterioration. ${ }^{1}$ Hence, the use of new sources of energy, especially in the transport sector, has become a priority. Bioethanol appears to be one of the most promising alternatives to fossil-derived fuels. Its production has increased all over the world in the past few years through expansion of existing plants and construction of new facilities. ${ }^{2}$ World fuel ethanol production in 2003 was $32 \mathrm{Mm}^{3}$. The major producers of ethanol are Brazil and the United States, which together account for about $80 \%$ of world production. The U. S. production of ethanol increased by an order of magnitude over the past 15 years, reached 13 billion gallons ( 49 billion liters) in 2010, and grew at $15-20 \%$ per year over the last two decades. ${ }^{3,4}$ Although most of the ethanol is currently produced from corn and other starch crops, the largest potential feedstock for ethanol is lignocellulosic biomass, which includes materials such as agricultural residues (e.g., corn stover, crop straws, sugar cane bagasse), herbaceous crops (e.g., alfalfa, switchgrass), forestry wastes, wastepaper, and other wastes.

The ethanol concentration as obtained in the fermentation broth is about $5 \mathrm{wt} \%$. To reach a concentration of ethanol equal to $99.7 \mathrm{wt} \%$ as specified for the European Union standards
(EN 15376) or 98.7 wt \% for the American Society for Testing and Materials (ASTM) standards, a significant amount of energy and high production costs are required. ${ }^{5,6}$ Several energydemanding separation steps are required to reach the purity target, mainly due to the presence of ethanol-water azeotrope (95.63\% wt ethanol at atmospheric pressure). Different alternatives are available and described in the literature: pervaporation, adsorption, pressure-swing distillation, extractive distillation, and azeotropic distillation as well as hybrid methods combining these options. Although distillation presents relatively high energy costs, it is still the preferred option in the case of large-scale productions. ${ }^{7}$

One common industrial alternative for ethanol dehydration is extractive distillation. ${ }^{7-12}$ Extractive distillation performs the separation in the presence of a miscible, high boiling point, relatively nonvolatile component that does not form any azeotrope with the other components in the mixture. For the extractive distillation of ethanol-water, ethylene glycol remains the most commonly used entrainer, although glycerol, hyperbranched polymers, and ionic liquids were also proposed. ${ }^{7}$ As reported in Figure 1, the classical extractive distillation sequence is composed by three columns.

The first, called preconcentration or prefractionator, is used to concentrate ethanol from 5-12 wt \% up to 92.4-94 wt \%. In the second column, the ethanol is dehydrated above the

Received: August 28, 2013

Revised: November 21, 2013

Accepted: November 22, 2013

Published: November 22, 2013 


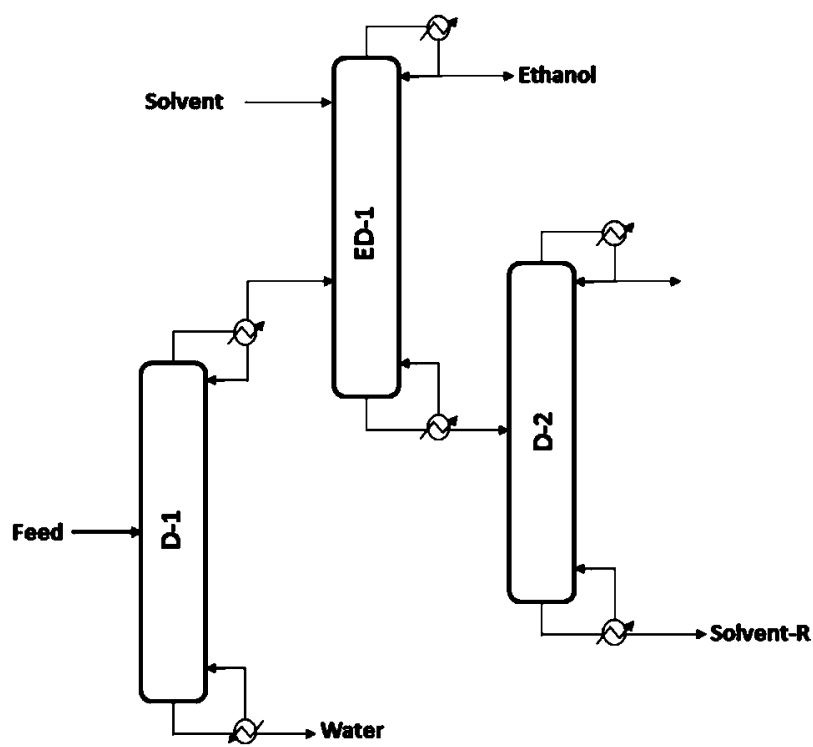

Figure 1. Classical extractive distillation process for ethanol dehydration.

azeotropic composition, and then in the third one, the solvent is recovered.

Extractive distillation is a promising separation opportunity, and the aim of this paper is to present a study about closedloop control policy, using PI controllers, for new distillation sequences for the ethanol dehydration recently proposed by Errico and Rong. ${ }^{11}$ These new distillation configurations were obtained following the principles of process intensification to save both energy and capital costs. The study of the control properties represents the last step in the analysis of those new configurations.

Contrary to the conventional distillation process, the dynamic behavior of extractive columns has been explored very little in published literature, although some authors have

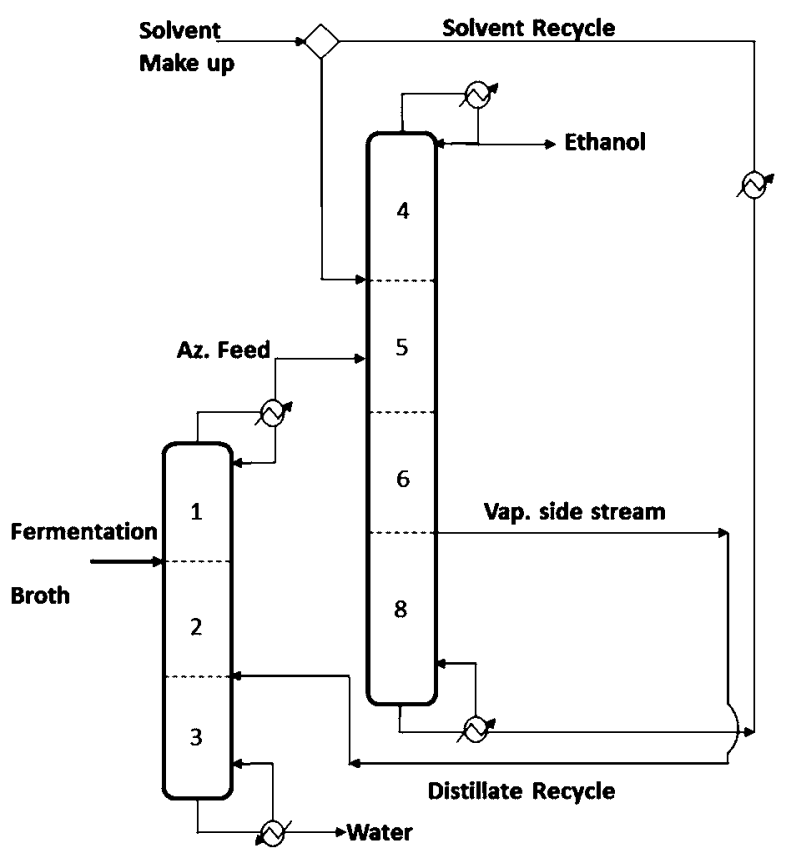

Figure 3. Two-column sequence (SSVR) with a vapor side stream.

approached this problem (Grassi II, ${ }^{13}$ Yao et al., ${ }^{14}$ Arifin and Chien, ${ }^{15}$ and Gutierrez-Guerra et al. ${ }^{16}$ ).

However, there are fewer studies focused on the dynamic behavior in extractive conventional distillation to produce anhydrous ethanol using glycerol or ethylene glycol as entrainer (Maciel and Brito ${ }^{17}$ and Gil et al. ${ }^{18}$ ). The evaluation done by Maciel and Brito ${ }^{17}$ of the dynamic behavior of the extractive conventional distillation of ethanol using ethylene glycol as the entrainer suggests good possibilities for control of the process. ${ }^{19}$

Another important point is that the control properties in extractive distillation columns are ruled by the kind of solvent used. The effect of the solvent in the control properties has

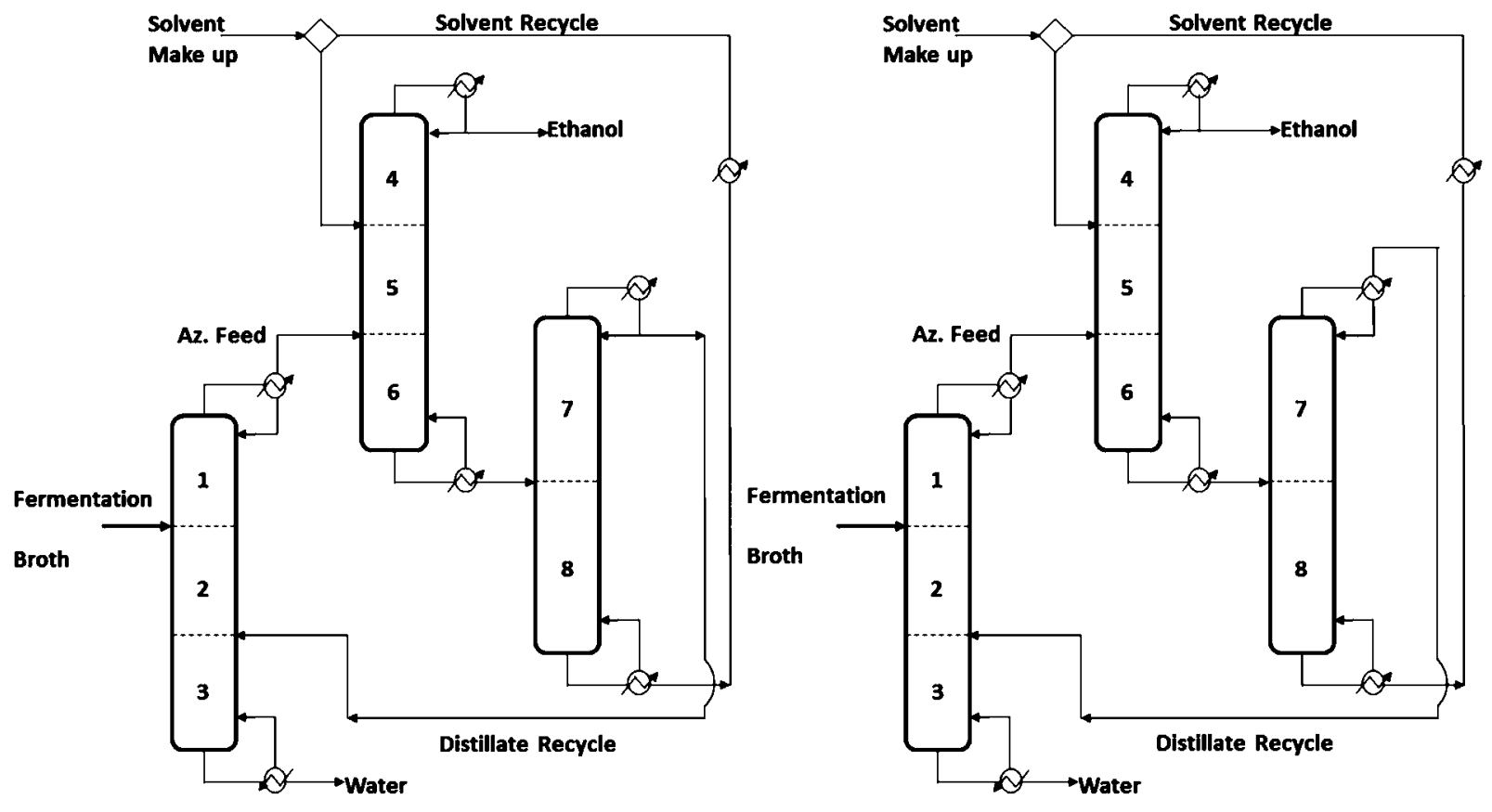

Figure 2. Conventional separation sequences (a) CLR with a liquid recycle and (b) CVR with a vapor recycle. 

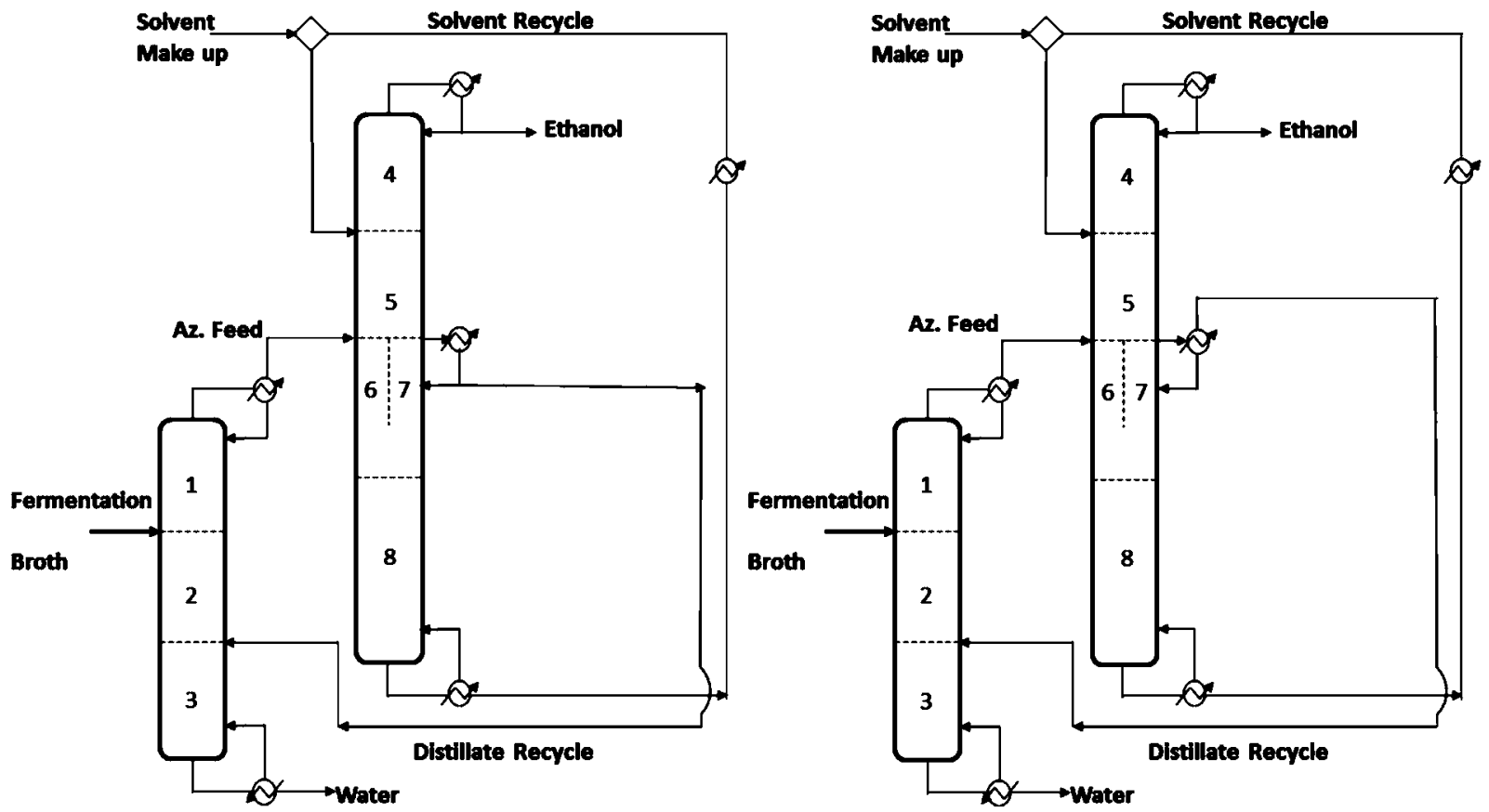

Figure 4. DWC/thermally coupled sequence (a) TCLR with a liquid recycle, (b) TCVR with a vapor recycle.
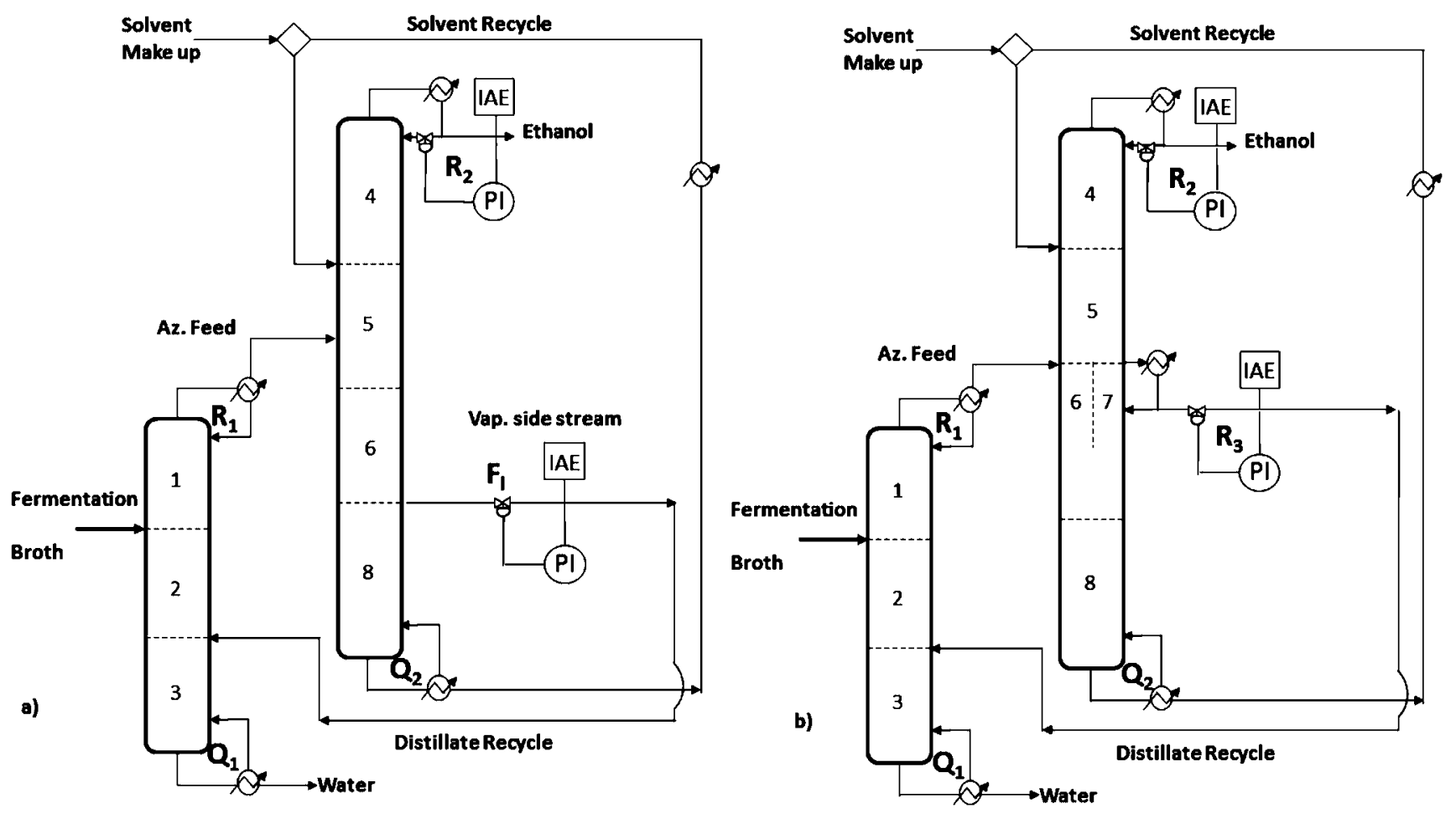

Figure 5. Loops LV: (a) two-column sequence (SSVR) with a vapor side stream and (b) TCLR with a liquid recycle.

been discussed previously by Luyben. ${ }^{20} \mathrm{~A}$ number of factors influence the selection of solvent: selectivity, solvent power, boiling point, and heat of vaporization. Also, controllability should be added to this list.

The purpose of this work is compare the dynamic behavior of alternative schemes of extractive distillation proposed by Errico and Rong ${ }^{11}$ to produce anhydrous ethanol using glycerol and ethylene glycol as entrainer. Taking advantage of these alternative schemes is characterized by a lower energy consumption compared to conventional extractive distillation schemes.

\section{CONFIGURATIONS ANALYZED}

Five sequences have been selected by considering their low energy requirements and the total annual cost. ${ }^{11}$ The first sequence, called CLR and is depicted in Figure 2a, consists of a prefractionator, in which water-ethanol mixture is partially separated until a purity close to the azeotrope is reached, 
Table 1. Mixture Analyzed and Component Properties

\begin{tabular}{ccccc} 
component & $\begin{array}{c}\text { feed composition } \\
(\text { mol fraction) }\end{array}$ & $\begin{array}{c}\text { boiling } \\
\text { point } \\
\left({ }^{\circ} \mathrm{C}\right)\end{array}$ & $\begin{array}{c}\text { critical } \\
\text { temperature } \\
\left({ }^{\circ} \mathrm{C}\right)\end{array}$ & $\begin{array}{c}\text { critical } \\
\text { pressure } \\
(\text { bar })\end{array}$ \\
\hline ethanol & 0.05 & 78.1 & 241 & 63 \\
water & 0.95 & 100 & 373.94 & 220.58
\end{tabular}

Table 2. Design Variables of SSVR

\begin{tabular}{lcc} 
& sections 1 to 3 & sections 4 to 8 \\
$\begin{array}{l}\text { number of stages } \\
\text { feed stage }\end{array}$ & 44 & 36 \\
$\begin{array}{l}\text { recycle stage } \\
\text { extractant stage }\end{array}$ & 30 & 25 \\
$\begin{array}{l}\text { distillate rate, } \mathrm{kmol} \mathrm{h}^{-1} \\
\text { bottom rate, } \mathrm{kmol} \mathrm{h}^{-1}\end{array}$ & 103.449 & 3 \\
$\begin{array}{l}\text { feed flow rate, } \mathrm{kmol} \mathrm{h}^{-1} \\
\text { recycle flow rate, } \mathrm{kmol} \mathrm{h}^{-1}\end{array}$ & 1609.178 & 85.037 \\
extractant flow rate, $\mathrm{kmol} \mathrm{h}^{-1}$ & 1694.24 & 51.145 \\
reflux ratio & 18.387 & 103.449 \\
temperature of distillate, ${ }^{\circ} \mathrm{C}$ & 2.011 & 51.12 \\
top pressure, bar & 78.212 & 0.189 \\
\hline
\end{tabular}

Table 3. Design Variables of DWC-TCLR with Ethylene Glycol

\begin{tabular}{|c|c|c|c|c|c|}
\hline & \multirow[b]{2}{*}{$\begin{array}{l}\text { sections } \\
1 \text { to } 3\end{array}$} & \multicolumn{3}{|c|}{ dividing wall column } & \multirow[b]{2}{*}{ section 8} \\
\hline & & section 4 & section 5 & $\begin{array}{l}\text { sections } \\
6 \text { and } 7\end{array}$ & \\
\hline number of stages & 44 & 5 & 20 & 10 & 7 \\
\hline feed stage & 30 & & 20 & & \\
\hline recycle stage & 30 & & & & \\
\hline extractant stage & & 5 & & & \\
\hline $\begin{array}{l}\text { distillate rate, } \\
\mathrm{kmol} \mathrm{h}^{-1}\end{array}$ & 100.200 & 84.165 & & & \\
\hline $\begin{array}{l}\text { bottom rate, } \\
\mathrm{kmol} \mathrm{h}^{-1}\end{array}$ & 1610.394 & & & & 86.521 \\
\hline $\begin{array}{l}\text { feed flow rate, } \\
\mathrm{kmol} \mathrm{h}^{-1}\end{array}$ & 1694.24 & & 100.2 & & \\
\hline $\begin{array}{l}\text { recycle flow rate, } \\
\mathrm{kmol} \mathrm{h}^{-1}\end{array}$ & 16.354 & & & & \\
\hline $\begin{array}{l}\text { extractant flow } \\
\text { rate, } \mathrm{kmol} \mathrm{h}^{-1}\end{array}$ & & 86.84 & & & \\
\hline reflux ratio & 2.325 & 0.235 & & & \\
\hline $\begin{array}{l}\text { temperature of } \\
\text { distillate, }{ }^{\circ} \mathrm{C}\end{array}$ & 77.863 & 77.976 & & & \\
\hline top pressure, bar & 1 & 1 & & & \\
\hline
\end{tabular}

followed by an extractive distillation column where, using an entrainer, pure ethanol is obtained as distillate. Finally, the solvent is recovered in the last column of the sequence. The distillate of the solvent recovery column consists of a waterethanol liquid mixture and is recycled back to the prefractionator. The CVR configuration reported in Figure $2 b$ has the same lay out of the previous one, but the water-ethanol
Table 5. Energy Requirements, Capital Costs, and Solvent Makeup for the Configuration Reported in Figure $2 b$ and in Figure 3 Using Glycerol As Entrainer

\begin{tabular}{lcc} 
& CVR-GL & SSVR-GL \\
total condenser duty $(\mathrm{kW})$ & 3820.645 & 3750.638 \\
total reboiler duty $(\mathrm{kW})$ & 5018.671 & 4934.136 \\
solvent makeup $\left(\mathrm{kmol} \mathrm{hr}^{-1}\right)$ & 0.001 & 0.010 \\
annualized capital cost $\left({\left.\mathrm{k} \$ \mathrm{yr}^{-1}\right)}^{134.3}\right.$ & 112.9 \\
\hline
\end{tabular}

Table 6. Optimum Closed Loops LV

\begin{tabular}{llrrc} 
& component & \multicolumn{1}{c}{$\mathrm{K}_{\mathrm{c}}$} & \multicolumn{1}{c}{$\mathrm{T}_{\mathrm{i}}$} & IAE \\
SSVR-GL & ethanol & 250.00 & 25.40 & 0.008570903 \\
& water & 25.00 & 3.00 & $4.90910 \times 10^{-04}$ \\
SSVR-EG & ethanol & 20.00 & 68.00 & 0.014097702 \\
& water & & & \\
CVR-GL & ethanol & 250.00 & 22.76 & 0.008675855 \\
& water & 175.00 & 8.75 & 0.002797684 \\
CVR-EG & ethanol & 250.00 & 55.00 & 0.010519718 \\
& water & 150.00 & 100.00 & 0.015901120 \\
CLR-EG & ethanol & 250.00 & 51.25 & 0.010172300 \\
& water & 10.00 & 139.75 & 0.050686177 \\
DWC/TCVR-EG & ethanol & 225.00 & 58.25 & 0.010521612 \\
& water & & & \\
DWC/TCLR-EG & ethanol & 250.00 & 52.00 & 0.011971880 \\
& water & 225.00 & 61.50 & 0.012179141 \\
\hline
\end{tabular}

mixture is recovered in the solvent recovery column as a vapor. Configurations CLR and CVR can be classified as conventional separation sequences. The third configuration analyzed SSVR, reported in Figure 3, belongs to the category of intensified sequences and consists of two columns, the prefractionator followed by the extractive distillation column with a side stream. In the extractive column, bioethanol is obtained at the top, the solvent is recovered at the bottom, and the vapor side stream contains a mixture of water and ethanol, which is recycled to the prefractionator. The fourth sequence, TCLR, consists of a DWC modeled by considering its equivalent thermally coupled configuration. As reported in Figure 4a, a liquid stream containing water and ethanol is recycled to the prefractionator. Ethanol is obtained as distillate of the main column while the solvent is recovered at the bottom. The fifth sequence, TCVR, reported in Figure $4 \mathrm{~b}$, is similar to the previous one but the recycled mixture ethanol-water is obtained in vapor phase.

Thus, the subspace of configurations under analysis includes the conventional sequences, the two-column sequence with a side stream, and the sequences with thermal couplings. Additionally, the influence of the entrainer type is also considered.

Table 4. Energy Requirements, Capital Costs, and Solvent Makeup for the Configurations Considered Using Ethylene Ethylene Glycol As Entrainer

\begin{tabular}{|c|c|c|c|c|c|}
\hline & CLR-EG & CVR-EG & SSVR-EG & TCLR-EG & TCVR-EG \\
\hline total condenser duty $(\mathrm{kW})$ & 4081.316 & 3871.042 & 3852.160 & 3970.814 & 3800.718 \\
\hline total reboiler duty $(\mathrm{kW})$ & 5118.425 & 4907.893 & 4902.925 & 5005.800 & 4837.323 \\
\hline solvent makeup $\left(\mathrm{kmol} \mathrm{hr}^{-1}\right)$ & 0.004 & 0.004 & 0.619 & 0.004 & 0.004 \\
\hline annualized capital cost $\left(\mathrm{k} \$ \mathrm{yr}^{-1}\right)$ & 132.8 & 133.1 & 107.8 & 102.3 & 102.6 \\
\hline
\end{tabular}


(a) Ethanol

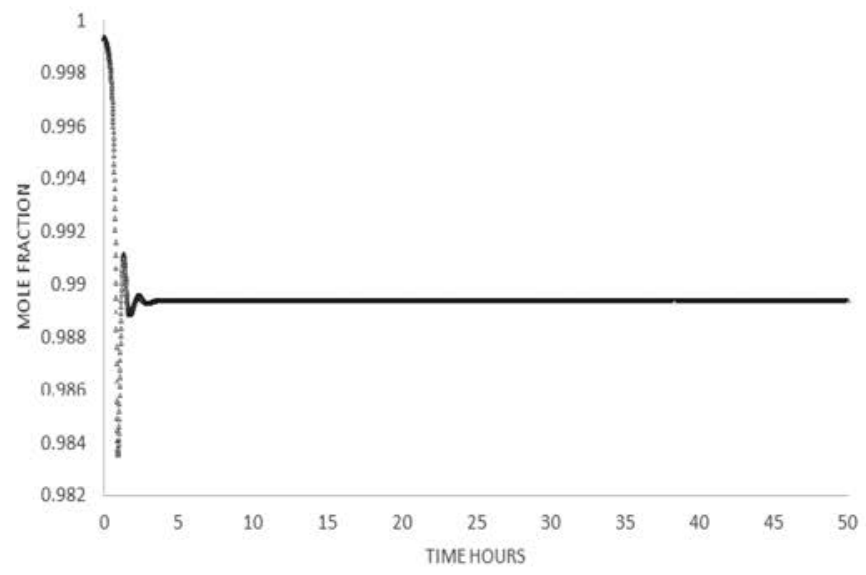

(c) Ethanol

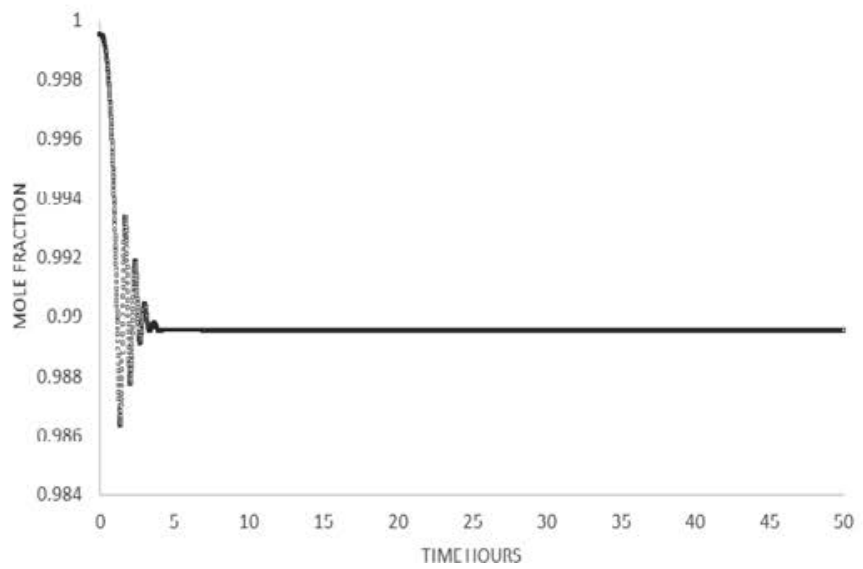

(b) Water

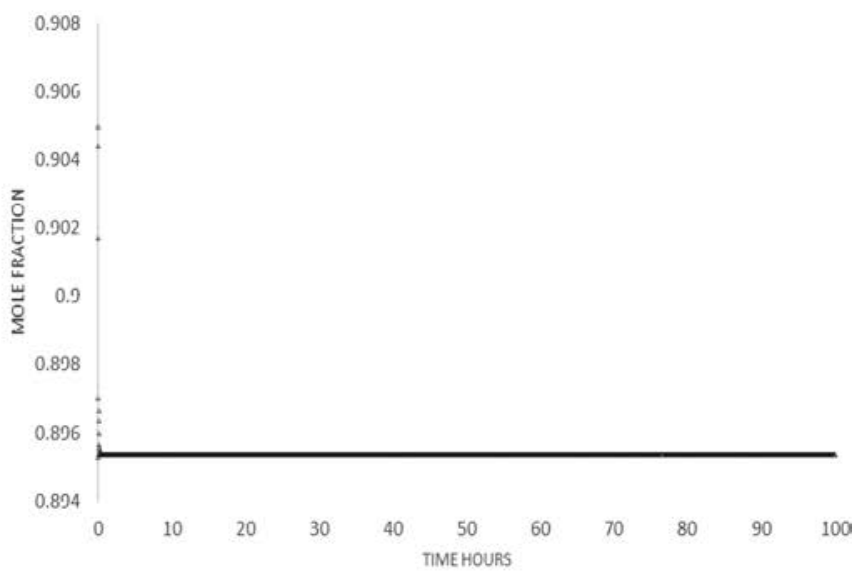

(d) Water

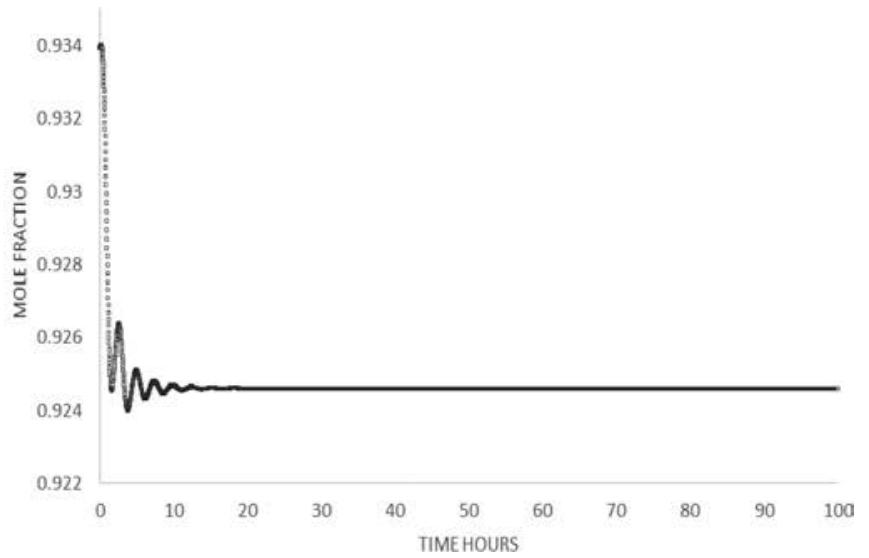

Figure 6. Dynamic responses: (a, b) SSVR sequence and (c, d) TCLR sequence.

\section{DYNAMIC ANALYSIS OF COMPLEX SEQUENCES}

For the closed-loop analysis, several issues must be defined first, such as the control loops for each system, the type of process controller to be used, and the values of the controller parameters. This analysis was based on proportional-integral (PI) controllers. The choice of the type of controller was based on the ample use that the proportional-integral (PI) mode has for distillation systems in the industrial practice. Several alternatives exist for tuning up the controller parameters. We attempted a common ground for comparison by optimizing the controller parameters, proportional gains $\left(K_{\mathrm{C}}\right)$, and reset times $\left(\tau_{\mathrm{i}}\right)$ for each conventional and integrated scheme following the integral of the absolute error (IAE) criterion. ${ }^{21}$

Therefore, for each loop, an initial value of the proportional gain was set; a search over the values of the integral reset time was conducted until a local optimum value of the IAE was obtained. The process was repeated for other values of the proportional gain. The selected set of controller parameters was then the one that provided a global minimum value of the IAE. Although the tuning procedure is fairly elaborate, the control analysis is conducted based on a common tuning method for the controller parameters. For the integrated arrangements, the procedure is particularly complicated because of the interactions of the multivariable control problem. For these cases, the tuning procedure was conducted taking one control loop at the time; the parameters thus obtained were taken for the following control loop until all the loops were considered.
For the dynamic analysis, individual set point changes for product composition were implemented for each of the two principal products streams: ethanol and water.

One of the key parts for the dynamic analysis is the selection of control outputs and manipulated variables for each control loop. A well-known structure is based on energy balance considerations, which yields to the so-called LV control structure in which the reflux flow rate $L$ and the vapor boilup rate $V$ (affected directly by the heat duty supplied to the reboiler) are used to control the distillate and bottom outputs compositions (Häggblom and Waller ${ }^{22}$ ). It should be mentioned that such control loops have been used with satisfactory results in previous studies on thermally coupled systems. ${ }^{23-26}$ The manipulated variables for the distillation columns were the corresponding reflux flow rates, reboiler heat duties, or side 0stream flow rate for the control composition of ethanol and water, (see, for example, Figure 5). Additionally, the pairing of same manipulated and control variables was obtained using the relative gain array method (RGA).

\section{CASE STUDY}

A diluted ethanol-water solution hypothetically produced from a fermentation process with a flow rate of $1694.24 \mathrm{kmol} \mathrm{hr}^{-1}$ and the composition reported in Table 1 is considered as a feed for all the cases considered. The NRTL method was utilized to evaluate the activity coefficients. Ethylene glycol was chosen as solvent. The ethanol minimum purity was set to 0.999 on a 


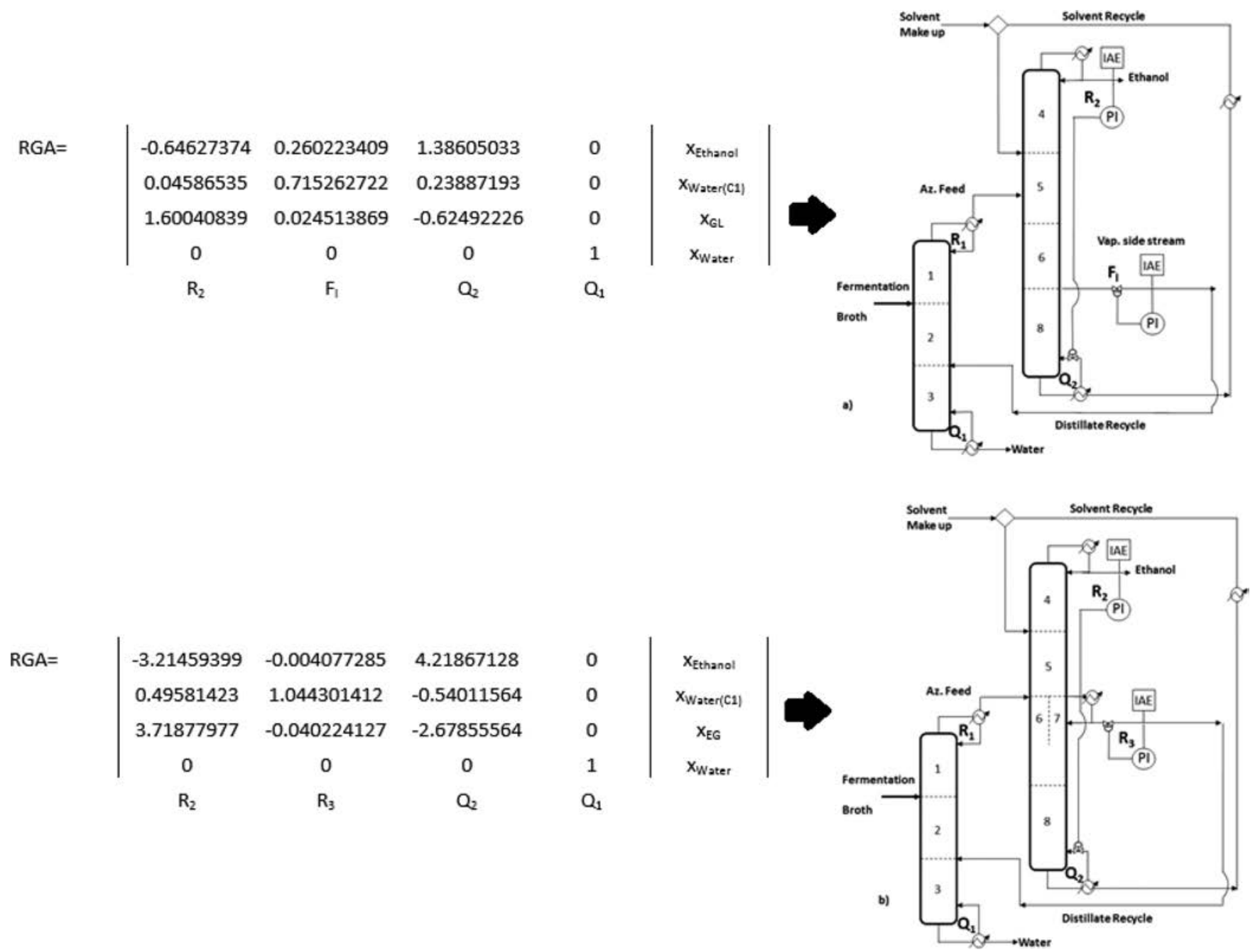

Figure 7. Matrix and schemes by RGA method for two-column sequence (SSVR) with vapor side stream and DWC-TCLR with liquid recycle with ethylene glycol as entrainer.

Table 7. Pairing Loops by LV and RGA Method in All Sequences

\begin{tabular}{|c|c|c|c|c|c|c|c|c|}
\hline & \multicolumn{4}{|c|}{ LV } & \multicolumn{4}{|c|}{ RGA } \\
\hline & $\mathrm{x}_{\text {ethanol }}$ & $\mathbf{x}_{\text {water(cl) }}$ & $\mathrm{x}_{\text {solvent }}$ & $\mathbf{x}_{\text {water }}$ & $\mathrm{x}_{\text {ethanol }}$ & $\mathbf{x}_{\text {water(cl) }}$ & $\mathrm{x}_{\text {solvent }}$ & $\mathrm{x}_{\text {water }}$ \\
\hline SSVR-GL & $\mathrm{R}_{2}$ & $\mathrm{~F}_{1}$ & $\mathrm{Q}_{2}$ & $\mathrm{Q}$ & $\mathrm{Q}_{2}$ & $\mathrm{~F}_{1}$ & $\mathrm{R}_{2}$ & $\mathrm{Q}$ \\
\hline SSVR-EG & $\mathrm{R}_{2}$ & $\mathrm{~F}_{1}$ & $\mathrm{Q}_{2}$ & $\mathrm{Q}$ & $\mathrm{F}_{1}$ & $\mathrm{Q}_{2}$ & $\mathrm{R}_{2}$ & $\mathrm{Q}$ \\
\hline CVR-GL & $\mathrm{R}_{2}$ & $\mathrm{R}_{3}$ & $\mathrm{Q}_{3}$ & $\mathrm{Q}$ & $\mathrm{R}_{2}$ & $\mathrm{R}_{3}$ & $\mathrm{Q}_{3}$ & $\mathrm{Q}$ \\
\hline CVR-EG & $\mathrm{R}_{2}$ & $\mathrm{R}_{3}$ & $\mathrm{Q}_{3}$ & $\mathrm{Q}_{1}$ & $\mathrm{R}_{2}$ & $\mathrm{R}_{3}$ & $\mathrm{Q}_{3}$ & $\mathrm{Q}$ \\
\hline CLR-EG & $\mathrm{R}_{2}$ & $\mathrm{R}_{3}$ & $\mathrm{Q}_{3}$ & $\mathrm{Q}$ & $\mathrm{R}_{2}$ & $\mathrm{R}_{3}$ & $\mathrm{Q}_{3}$ & $\mathrm{Q}$ \\
\hline DWC/TCLR-EG & $\mathrm{R}_{2}$ & $\mathrm{R}_{3}$ & $\mathrm{Q}_{2}$ & $\mathrm{Q}$ & $\mathrm{Q}_{2}$ & $\mathrm{R}_{3}$ & $\mathrm{R}_{2}$ & $\mathrm{Q}$ \\
\hline DWC/TCVR-EG & $\mathrm{R}_{2}$ & $\mathrm{R}_{3}$ & $\mathrm{Q}_{2}$ & $\mathrm{Q}$ & $\mathrm{R}_{3}$ & $\mathrm{Q}_{2}$ & $\mathrm{R}_{2}$ & $\mathrm{Q}$ \\
\hline
\end{tabular}

molar fraction basis to enable its use blended with oil derived fuels. According to the work of Errico et al., ${ }^{27,28}$ the configurations considered were first simulated utilizing the WinnUnderwood-Gilliland shortcut method, then the design parameters were optimized, minimizing the heat duty. A solvent to feed ratio of 0.87 was employed in all the configurations simulated. The solvent recovery column was designed in order to minimize the makeup flow rate. The installation cost evaluation was performed with Aspen Plus Economic Analyzer. Some representative designs are displayed in Tables 2 and 3. The energy consumption, the capital costs, and the solvent makeup flow rate for the configurations reported in Figures 2-4 are summarized in Table 4. It is possible to notice that the divided wall configurations are promising options to reduce the energy and capital costs even if, with their structural complexity, a dynamic analysis is essential. Another interesting configuration is the SSVR. Analyzing the solvent makeup flow rate reported in Table 4, it is evident that the SSVR has a high solvent consumption because of the presence of the side stream. The convenience to employ this type of configuration can be evaluated as a difference between the energy and capital costs saved compared to the traditional sequences and the increase of the solvent consumption. For this reason, the configurations CVR and SSVR were simulated again by using glycerol as entrainer. 
Table 8. Optimum Closed Loops and Energy Consumption, $\mathrm{CO}_{2}$ Emissions, Toxicity, and Cost of Solvent Used for All Analyzed Sequences

\begin{tabular}{|c|c|c|c|c|c|c|}
\hline & \multicolumn{2}{|c|}{ control } & \multirow[b]{2}{*}{ total reboiler duty $[\mathrm{kW}]$} & \multirow[b]{2}{*}{ emissions $\mathrm{CO}_{2}$ [tons/hour] } & \multirow[b]{2}{*}{ toxicity category $^{c}$} & \multirow[b]{2}{*}{ solvent cost $[$ dollar $/ \mathrm{kg}]$} \\
\hline & IAE ethanol & IAE water & & & & \\
\hline SSVR-GL & $0.008570903^{a}$ & $4.90910 \times 10^{-04 a}$ & 5118.425 & 23.93034 & 0 & 0.825 \\
\hline SSVR-EG & $0.014097702^{a}$ & $8.48955 \times 10^{-05 b}$ & 4907.893 & 67.71364 & 5 & 2 \\
\hline CVR-GL & $0.008675855^{a}$ & $2.79768 \times 10^{-03 a}$ & 4902.925 & 24.11146 & 0 & 0.825 \\
\hline CVR-EG & $0.010519718^{a}$ & $1.59011 \times 10^{-02 a}$ & 5005.800 & 25.01390 & 5 & 2 \\
\hline CLR-EG & $0.010172300^{a}$ & $5.06862 \times 10^{-02 a}$ & 4837.323 & 26.06645 & 5 & 2 \\
\hline DWC/TCVR-EG & $0.010521612^{a}$ & $9.63112 \times 10^{-03 b}$ & 5018.671 & 28.14349 & 5 & 2 \\
\hline DWC/TCLR-EG & $0.011971880^{a}$ & $1.21791 \times 10^{-02 a}$ & 4934.136 & 27.81083 & 5 & 2 \\
\hline
\end{tabular}

Glycerol is a cheaper solvent that can be obtained as a byproduct from biodiesel plants. The results, when glycerol is used as entrainer, are summarized in Table 5.

\section{RESULTS}

The prediction of the transient response of a distillation column bears much importance in the sense of the effective control of the separation process. ${ }^{29}$ Such resulting structures obtained with the main target of the energy savings provided the configurations that were subjected to the dynamic analysis. For all cases, two control loops were assumed to operate in a closedloop fashion. The performance of the sequences under analysis was compared through the evaluation of IAE values for each test.

Table 6 shows the IAE values obtained for each composition control loop of the eight cases considered using LV configuration in closed loop (see, for example, Figure 5).

The two-column sequence with a vapor side stream (SSVRGL) exhibited the best performances, based on the lowest values of IAE, for the control of the two product streams. The conventional column sequence (CVR-GL) exhibited good dynamic performance based in the IAE value for the ethanol loop. However, it presents the worst dynamic behavior in the water loop in comparison with the SSVR-GL configuration (see Figure 6). The worst performances are observed when ethylene glycol is used with the conventional sequences (CLR-EG and CVR-EG) and the thermally coupled sequences (DWC-TCVR and DWC-TCVR), based on the values of IAE (Table 6). An important point to note is that for sequences SSVR and DWCTCLR using ethylene glycol as entrainer and under the LV control structure and under the tuning methodology used in this work, it was not possible to find the values of $K_{\mathrm{C}}$ and $\tau_{\mathrm{I}}$ to stabilize the dynamic response for water.

To complete the study of the control properties, relative gain arrays (RGA) were obtained for all sequences analyzed. Figure 7 shows the RGA results and the schemes for some representative sequences. As we can see, the complex sequence presents interactions because positive values of the relative gains are greater than 1 . Also, the negative values cause negative interactions. In general, from relative gain arrays for all cases of study, we can conclude that significant interactions are present in all distillation sequences studied. We use the relative gain array method to fix other loops for the control system. One representative case, shown in Table 7 , displays a comparison between loops proposed by LV and RGA study. The IAE values were reported for both cases (LV and RGA control structure) in Table 8 for optimum control behavior. The loops proposed by RGA structure, in the case of SSVR and DWC-TCLR and using ethylene glycol as entrainer, are better than LV control loops. This shows that under this configuration, it was possible for these two sequences stabilize the control loop of water. Recall that it was not possible to stabilize this loop in the LV configuration.

The effect of the solvent on the control properties has been discussed previously by Luyben. ${ }^{20}$ Under these arguments, it is understandable that in our case study, the kind of solvent affects the dynamic performance and the selection of the loop configuration of the systems.

In Table 8, a summary of the results obtained in this study is reported. It is important to include both the toxicity (and cost) of the solvent and the amount of $\mathrm{CO}_{2}$ emissions generated in the heating of reboiler of the columns, because they even pretend to have the best integral design. Sometimes it is possible to get the best settings in dynamic performance but the design can be operating with high $\mathrm{CO}_{2}$ emissions levels, or it might also be using a very toxic (or expensive) extracting agent. For those reasons, it is necessary to do a global analysis and selection of all parameters associated with the design structure and dynamic behavior of the system.

The results from the dynamic behavior (based in IAE values) indicate that the presence of a side stream does not necessarily provide operational disadvantages, as originally expected because of the resulting complex structural design. Also, in general, configurations with a side stream and the conventional sequences using glycerol as a solvent outperformed the dynamic behavior of the DWC schemes, the energy consumption, $\mathrm{CO}_{2}$ emissions, cost, and toxicity of entrainer. The greenhouse emissions were calculated as proposed by Gadalla et al. ${ }^{30}$

\section{CONCLUSIONS}

A study on the dynamic behavior of alternative extractive distillation sequences for the purification of bioethanol has been presented. Results from the closed-loop-fashion process indicated that, in general, configurations with a vapor side stream and the conventional sequences using glycerol as solvent are the best options. One factor seems to affect the optimal choice: the kind of solvent used as entrainer. The better performances of the sequences with glycerol compare to the ethylene glycol promote the use of sustainable solvents even more. In general, it is worthwhile to notice that the presence of side streams, instead of deteriorating the dynamic behavior of extractive distillation systems for this case of study, may contribute positively to their dynamic properties. In general, those alternative extractive distillation arrangements with complex structures can be a good option for industrial use due to a good dynamic behavior and the reduction in energy consumption. 


\section{AUTHOR INFORMATION}

\section{Corresponding Author}

*J. G. Segovia-Hernández. Tel.: +52(473)7320006. E-mail: gsegovia@ugto.mx.

\section{Notes}

The authors declare no competing financial interest.

\section{ACKNOWLEDGMENTS}

This research project was supported by a project SAGARPACONACyT-174560, (Universidad Michoacana de San Nicolás de Hidalgo and Universidad de Guanajuato, México). The authors gratefully acknowledge Sardinia Regional Government for the financial support (P.O.R. Sardegna F.S.E. Operational Programme of the Autonomous Region of Sardinia, European Social Fund 2007-2013-Axis IV Human Resources, Objective 1.3, Line of Activity 1.3.1 "Avviso di chiamata per il finanziamento di Assegni di Ricerca”).

\section{REFERENCES}

(1) Tan, K. T.; Lee, K. T.; Mohamed, A. R. Role of Energy Policy in Renewable Energy Accomplishment: The Case of Second-Generation Bioethanol. Energy Policy 2008, 36, 3360.

(2) Karuppiah, R.; Peschel, A.; Grossmann, I. E.; Martín, M.; Martinson, W.; Zullo, L. Energy Optimization for the Design of CornBased Ethanol Plants. AIChE J. 2008, 54, 1499.

(3) Kim, S.; Dale, B. E. Environmental Aspects of Ethanol Derived from No-Tilled Corn Grain: Nonrenewable Energy Consumption and Greenhouse Gas Emissions. Biomass Bioenergy 2005, 28, 475.

(4) Wallington, T. J.; Anderson, J. E.; Mueller, S. A.; Kolinski Morris, E.; Winkler, S. L.; Ginder, J. M. Corn Ethanol Production, Food Exports, and Indirect Land Use Change. Environ. Sci. Technol. 2012, 46, 6379.

(5) Vane, L. M. Separation Technologies for the Recovery and Dehydration of Alcohols from Fermentation Broths. Biofuels, Bioprod. Biorefin. 2008, 2, 553.

(6) Gudena, K.; Rangaiah, G. P.; Lakshminarayanan, S. HiGee Stripper-Membrane System for Decentralized Bioethanol Recovery and Purification. Ind. Eng. Chem. Res. 2013, 52, 4572.

(7) Kiss, A. A. Novel Applications of Dividing-Wall Column Technology to Biofuel Production Processes. J. Chem. Technol. Biotechnol. 2013, 88, 1387.

(8) Ravagnani, M. A. S. S.; Reis, M. H. M.; Maciel-Filho, R.; WolfMaciel, M. R. Anhydrous Ethanol Production by Extractive Distillation: A Solvent Case Study. Process Saf. Environ. Prot. 2010, $88,67$.

(9) Avilez-Martínez, A.; Saucedo-Luna, J.; Segovia-Hernández, J. G.; Hernández, S.; Gómez-Castro, F. I.; Castro-Montoya, A. J. Dehydration of Bioethanol by Hybrid Processes Liquid-Liquid Extraction/Extractive Distillation. Ind. Eng. Chem. Res. 2012, 51, 5847.

(10) Kiss, A. A.; Suszwalak, D.J.-P.C. Enhanced Bioethanol Dehydration by Extractive Distillation in Dividing-Wall Columns. Sep. Purif. Technol. 2011, 86, 70.

(11) Errico, M.; Rong, B.-G. Synthesis of New Separation Processes for Bioethanol Production by Extractive Distillation. Sep. Purif. Technol. 2012, 96, 58.

(12) Vázquez-Ojeda, M.; Segovia-Hernández, J. G.; Hernández, S.; Hernández-Aguirre, A.; Kiss, A. A. Design and Optimization of an Ethanol Dehydration Process Using Stochastic Methods. Sep. Purif. Technol. 2013, 105, 90.

(13) Grassi II, V. G. Process Design and Control of Extractive Distillation, in Practical Distillation Control; Luyben, W. L., Ed.; Van Nostrand Reinhold: New York, 1992.

(14) Yao, J. Y.; Lin, S. Y.; Chien, I. L. Operation and control of batch extractive distillation for the separation of mixtures with minimumboiling azeotrope. J. Chin. Inst. Chem. Eng. 2007, 38, 371.
(15) Arifin, S.; Chien, I. L. Design and control of an isopropyl alcohol dehydration process via extractive distillation using dimethyl sulfoxide as an entrainer. Ind. Eng. Chem. Res. 2008, 47, 790.

(16) Gutiérrez-Guerra, R.; Segovia-Hernández, J. G.; Hernández, S. Reducing energy consumption and $\mathrm{CO}_{2}$ emissions in extractive distillation. Chem. Eng. Res. Des. 2009, 87, 145.

(17) Maciel, M. R. W.; Brito, R. P. Evaluation of the Dynamic Behavior of an Extractive Distillation Column for Dehydration of Aqueous Ethanol Mixtures. Comput. Chem. Eng. 1995, 19 (Suppl. 1), 405-408.

(18) Gil, I. D.; Gómez, J. M.; Rodríguez, G. Control of an Extractive Distillation Process to Dehydrate Ethanol Using Glycerol as Entrainer. Comput. Chem. Eng. 2012, 39, 129-142.

(19) Ramos, M. A.; García-Herreros, P.; Gómez, J. M. Optimal Control of the Extractive Distillation for the Production of Fuel-Grade Ethanol. Ind. Eng. Chem. Res. 2013, A-Q.

(20) Luyben, W. L. Effect of solvent on controllability in extractive distillation. Ind. Eng. Chem. Res. 2008, 47, 4425.

(21) Stephanopoulos, G. Chemical Process Control: An Introduction to Theory and Practice; Prentice Hall: Englewood Cliffs, NJ, 1984.

(22) Häggblom, K. E.; Waller, K. V. Control Structures, Consistency, and Transformations. In Practical Distillation Control; Luyben, W. L., Ed.; Van Nostrand Reinhold: New York, 1992.

(23) Jiménez, A.; Hernández, S.; Montoy, F. A.; Zavala-García, M. Analysis of Control Properties of Conventional and Nonconventional Distillation Sequences. Ind. Eng. Chem. Res. 2001, 40, 3757.

(24) Segovia-Hernández, J. G.; Hernández, S.; Jiménez, A. Control Behaviour of Thermally Coupled Distillation Sequences. Chem. Eng. Res. Des. 2002, 80 (Part A), 783.

(25) Segovia-Hernández, J. G.; Hernández, S.; Rico-Ramírez, V.; Jiménez, A. A Comparison of the Feedback Control Behavior between Thermally Coupled and Conventional Distillation Schemes. Comput. Chem. Eng. 2004, 28, 811.

(26) Segovia-Hernández, J. G.; Hernández, S.; Femat, R.; Jiménez, A. Control of Thermally Coupled Distillation Sequences with Dynamic Estimation of Load Disturbances. Ind. Eng. Chem. Res. 2007, 46, 546.

(27) Errico, M.; Rong, B.-G.; Tola, G.; Spano, M. Optimal Synthesis os Distillation Systems for Bioethanol Separation. Part 1: Extractive Distillation with Simple Columns. Ind. Eng. Chem. Res. 2013 a, 52, 1619.

(28) Errico, M.; Rong, B.-G.; Tola, G.; Spano, M. Optimal Synthesis os Distillation Systems for Bioethanol Separation. Part 2: Extractive Distillation with Complex Columns. Ind. Eng. Chem. Res. 2013 b, 52, 1626.

(29) Berber, R.; Karadurmus, E. Dynamic Simulation of a Distillation Column Separating a Multicomponent Mixture. Chem. Eng. Commun. 1989, 84, 113.

(30) Gadalla, M. A.; Olujic, Z.; Jansens, P. J.; Jobson, M.; Smith, R. Reducing $\mathrm{CO}_{2}$, Emissions and Energy Consumption of HeatIntegrated Distillation Systems. Environ. Sci. Technol. 2005, 39, 6860. 